\title{
Synthesis and Morphological Characterization of Nickel-Zinc Oxide Composites using Solid State Method
}

\author{
Sani Garba Danjumma \\ Department of Sciences \\ Kebbi State Polytechnic, Dakingari, \\ Nigeria \\ Sirajo Abdullahi \\ Department of Physics \\ Kebbi State University of Science and Technology, \\ Aliero, Nigeria
}

\begin{abstract}
Some properties of materials are functions of their microstructures, and, consequently, of their thermal histories. It is often the case that these properties are more desirable than those associated with the equilibrium state. Many times, the physical properties and, in particular, the mechanical behaviour of a material depend on the microstructure. Microstructure is subject to direct microscopic observation, using optical or electron microscopes. The synthesis of a doped zinc-oxide composites using simple solid stated method was successfully carried out in this research. Characterization were carried out for the surface morphology and bonding of the composites using SEM and FTIR, respectively. The result from SEM was able to distinguish between the filler and matrix for each composition. The result also revealed agglomeration of particles as doping increased for all compositions. As doping increased to higher quantity, density of sample increased and this allowed for the faster propagation of light through the sample, which is evident in the FTIR analysis. All results obtained were promising for microwave absorption applications.
\end{abstract}

Key Words: Synthesis, Morphological, Characterization, NickelZinc Oxide, Composites

\section{INTRODUCTION}

Composites are artificially produced multiphase materials having a desirable combination of the best properties of the constituent phases. With knowledge of the various types of composites, as well as an understanding of the dependence of their behaviours on the characteristics, relative amounts, geometry/distribution, and properties of the constituent phases, it is possible to design materials with property combinations that are better than those found in the metal alloys, ceramics, and polymeric materials. $\mathrm{ZnO}$ is a wide band gap $(3.2 \mathrm{eV})$ n-type semiconductor that has found a wide range of applications as a transparent conducting oxide (TCO) electrode in photovoltaics, photocatalysis, sensing, fuel cells and other optoelectronic devices (Albert \& Abiola, 2017). Umit, (2010), reported that, $\mathrm{ZnO}$ is an attractive material for applications in electronics, photonics, acoustics, and sensing. In optical emitters, its high exciton binding energy $(60 \mathrm{meV})$ gives $\mathrm{ZnO}$ an edge over other semiconductors such as $\mathrm{GaN}$ if reproducible and reliable ptype doping in $\mathrm{ZnO}$ were to be achieved, which currently

\author{
Abubakar Yakubu \\ Department of Physics \\ Kebbi State University of Science and Technology, \\ Aliero, Nigeria \\ Saidu Aliyu \\ Department of Sciences \\ Kebbi State Polytechnic, Dakingari, \\ Nigeria
}

remains to be the main obstacle for realization of bipolar devices. On the electronic side, $\mathrm{ZnO}$ holds some potential in transparent thin film transistors (TFTs) owing to its high optical transmittivity and high conductivity.

$\mathrm{NiO}$ is a p-type wide band gap $(4.2 \mathrm{eV})$ semiconductor that has been used in similar applications. $\mathrm{ZnO}$ and $\mathrm{NiO}$ readily form a p-n junction that has shown good electrical properties for gas sensing, fuel cell electrodes and photocatalysis (Albert and Abiola, 2017). The applications of Nickel oxide (NiO) today is found in semiconductors, capacitor-inductor devices, tuned circuits, transparent heat mirrors, thermistors and varistors, batteries, micro-supercapacitors, electrochromic and chemical or temperature sensing devices. It is used in preparation of nickel cermet, plastics and textiles, in nanowires, nanofibers and specific alloy and catalyst applications. It is also used as an antiferromagnetic layers, accelerators and radar absorbing materials, aerospace and active optical filters (Sani et al., 2019; AzoNano, 2013). Sónia et al. (2017), focuses on the production by powder metallurgy of aluminum and nickel matrix composites reinforced by CNTs, using ultrasonication as the dispersion and mixture process. Microstructural characterization of nanocomposites was performed by scanning and transmission electron microscopy (SEM and TEM) and the result revealed that, $\mathrm{CNT}$ clusters at grain boundary junctions were also observed. Abdul et al. (2017), in their work describes the fabrication of $\mathrm{Ni}$-graphene composite coatings on carbon steel at different deposition temperatures $\left(15^{\circ} \mathrm{C}, 30^{\circ} \mathrm{C}, \quad 45^{\circ} \mathrm{C}\right.$ and $60^{\circ} \mathrm{C}$, respectively) by an electrochemical co-deposition method. The surface morphology was examined by scanning electron microscopy (SEM), and the results showed that the $\mathrm{Ni}$-graphene composite coatings deposited at $45^{\circ} \mathrm{C}$ exhibit coarser surface morphology with increased carbon content.

Nickel/cobalt double hydroxides with sphere-like nanoflowers and nanoporous structures were controllably prepared by introducing halide ions into the reaction system. The morphology and structure of the composites were characterized by X-ray diffraction, scanning electron microscope, infrared spectra and Brunauer-Emmett-Teller method. Halides, especially bromide, can dramatically affect the morphology of the crystal aggregates, and some 
morphology-dependent electrochemical properties are found (Yuqing, 2018).

Dispersion of $2 \mathrm{D}$ carbon nitride $\left(\mathrm{C}_{3} \mathrm{~N}_{4}\right)$ nanosheets into a nickel phosphorous (NiP) matrix was successfully achieved by ultrasonication during the electroless plating of $\mathrm{NiP}$ from an acidic bath. The morphology and thickness were determined by scanning electron microscopy and energydispersive X-ray spectroscopy. $\mathrm{C}_{3} \mathrm{~N}_{4}$ showed a homogeneous distribution morphology in the nanocomposite that changed from amorphous in case of the $\mathrm{NiP}$ to a mixed crystalline-amorphous structure in the NiP$\mathrm{C}_{3} \mathrm{~N}_{4}$ nanocomposite (Eman et al., 2018).

Synthesized NiO are used to prepare Polyaniline (PANI)$\mathrm{NiO}$ nanocomposites by in situ chemical oxidative polymerization at 0-50C. Different weight percentages of $\mathrm{NiO}$ were added during the polymerization. PureNiO, shows small spherical shaped Pure NiO. PN-5 shows the encapsulation of $\mathrm{NiO}$ nano particles by polyaniline with flower like structure. PN-20 and PN-40 depicts spherical shaped structures with cluster formation. FTIR shows weak Van der Waals forces of attraction between metal oxide and polymerised aniline (Rajashekhar et al., 2015). Kazuaki et al., (2011), reported that, the SEM of NZF/PEG (Ni-Zn ferrite/pentaerythritol tetra-polyethylene glycol ether) and $\mathrm{NZF/ER} \mathrm{composites,} \mathrm{revealed} \mathrm{voids} \mathrm{between} \mathrm{particles} \mathrm{are}$ observed. On the other hand, they are not found in the NZFN/PEG composite; therefore, NZFN/PEG composites can be formed a densely-packed microstructure.

The FTIR spectra for pure PVA, ZnO/ PVA nanocomposite films and $\mathrm{ZnO}$ are reported by Mansour, et al. (2014). In the spectra of pure PVA and $\mathrm{ZnO} / \mathrm{PVA}$ nanocomposites, the broad and strong band centered at $3340 \mathrm{~cm}^{-1}$ is assigned to the stretching vibration of hydroxyl group $(\mathrm{OH})$. The strong band at $2940 \mathrm{~cm}-1$ is assigned to the band of asymmetric $\mathrm{CH}_{2}$ stretching. The two bands observed at 1712 and 1658 $\mathrm{cm}-1$ are assigned to the stretching vibrational band of $\mathrm{C}=\mathrm{O}$. The two bands observed at 1427 and $1330 \mathrm{~cm}-1$ are assigned as $\mathrm{CH}_{3}$ bending vibration and $\mathrm{CH} 2$ stretching respectively. The band at $1090 \mathrm{~cm}^{-1}$ arises from the $\mathrm{C}-\mathrm{O}$ stretching vibration while the band at $920 \mathrm{~cm}-1$ results from $\mathrm{CH}_{2}$ rocking vibration. Also, the band at $850 \mathrm{~cm}^{-1}$ result from $\mathrm{C}-$ $\mathrm{C}$ stretching vibration and that at $660 \mathrm{~cm}^{-1}$ arises from out of plane $\mathrm{OH}$ bending. The band at $432 \mathrm{~cm}^{-1}$ is assigned to the stretching vibration of $\mathrm{Zn}-\mathrm{O}$ bond. FTIR spectra of PVA, $\mathrm{ZnO}$ and $\mathrm{ZnO} / \mathrm{PVA}$ nanocomposites indicating that there are no interactions between polyvinyl alcohol and zinc oxide in forming nanocomposites.

The effect of $\mathrm{SiO}_{2}$ addition on the properties of $\mathrm{ZnO}-\mathrm{NiO}$ composite were investigated by Osama et al. (2014). They reported that, the SEM of their sample, shows the segregation of the intergranular phase in patches. This is evident from the different shades displayed varying from dark grey - light grey and white. The samples were of very dense microstructure. Although some pores were present, they were very small and separated from one another. The decrease of grain size is attributed to the precipitation of secondary phase in the grain boundaries and nodal points. The $\mathrm{ZnO}$ grains are homogeneous, $\mathrm{NiO} \mathrm{SiO}_{2}$ particles are small and distributed at the boundary of the $\mathrm{ZnO}$ grains.
Shanavas et al., (2019), repoted the surface images of PANI, $\mathrm{ZnO}$ nanoparticles, and $\mathrm{PANI} / \mathrm{ZnO}$ nanocomposite. The SEM image of PANI; has various structures such as granules, nanofibers, nanotubes, nanospheres, and microsphere. The diameter of PANI is approximately $100 \mathrm{~nm}$, and they have an irregular road-like morphology. The morphology of PANI has changed by the introduction of $\mathrm{ZnO}$ nanoparticles, it can be concluded that a thin layer of PANI molecules was adsorbed on the surface of $\mathrm{ZnO}$ nanoparticles, and a core-shell structure of $\mathrm{ZnO} / \mathrm{PANI}$ nanocomposite with the core of $\mathrm{ZnO}$ inorganic nanoparticle and the shell of monolayer PANI chains has been formed. The $\mathrm{ZnO}$ nanoparticles have a crystalline spherical structure. They went further to report that, the FTIR spectrum of $\mathrm{ZnO}$ nanoparticles in which the characteristic peaks at $430 \mathrm{~cm}^{-1}$ and $496 \mathrm{~cm}^{-1}$ is related to the $\mathrm{Zn}-\mathrm{O}$ stretching mode. According to the patterns, absorption intensity is increased by adding $\mathrm{ZnO}$ nanoparticles in the case of nanocomposites due to the uniform distribution of $\mathrm{ZnO}$ nanoparticles in nanocomposite matrix and elimination of agglomeration.

Jacek et al. (2018), present selected representative SEM images of $\mathrm{Zn}_{0.9} \mathrm{Co}_{0.1} \mathrm{O}$ NPs samples. An impact of the change of $\mathrm{H}_{2} \mathrm{O}$ content in the precursor on the morphology and size of $\mathrm{Zn}_{0.9} \mathrm{Co}_{0.1} \mathrm{O}$ NPs was observed. Powders obtained from the precursor with the water contents of $1.5 \%$ and $2 \%$ are composed of compact structures resembling a "cauliflower" structure. NPs obtained from the precursor with the $\mathrm{H}_{2} \mathrm{O}$ content of 3, 4, and 5\% had a homogeneous and loose structure.

Various layers with different $\mathrm{ZnO}$ nanopowder/grapheme nanoplatelets content, the respective ratio varying between 0.33 and 1.5 , were prepared and studied by Drakakis et al. (2018). They present SEM images of the commercial graphene nanoplatelets, the composite with the lowest $\mathrm{ZnO}$ nanopowder concentration and the composite with the highest $\mathrm{ZnO}$ nanopowder concentration. The images indicate that all the materials are very conductive (they are quite transparent for the electron beam) and the graphene flakes are quite flat even in the composite. Composite materials are homogeneous and $\mathrm{ZnO}$ has a more or less uniform distribution in the composites bulk as small agglomerations, which are more pronounced in the case of the highest $\mathrm{ZnO}$ nanopowder concentration. Moreover, the graphene flakes keep their general aspect in the composite materials (they don't agglomerate or crinkle very much), being decorated with $\mathrm{ZnO}$ nanoparticles agglomerations. Most of the researches reported did not explore the suitability of their composites in microwave absorption. For this reason, the suitability of the prepared composites is characterized to study its suitability in microwave absorption.

\section{SAMPLE PREPARATION}

In our work, the solid state method is used in the preparation of a doped zinc oxide. The materials used for the synthesis are $100 \mathrm{~g}$ of Zinc oxide (99.7\% purity) and $50 \mathrm{~g}$ of Nickel oxide (99.7\% purity) all in powdered form. The Zinc oxide was obtained at Halishuaib Chemicals while the Nickel oxide was obtained at CEMAN Chemicals Ventures. During the preparation of the composites, $5 \mathrm{~g}$ of Nickel oxide was 
mixed with $25 \mathrm{~g}$ of Zinc oxide using pestle and mortar, the combination was grinded continuously using mortar and pestle for about 60 minutes for perfect homogeneity. The mixed sample was taken to furnace and was heated to about $1000^{\circ} \mathrm{C}$ for appreciable reaction to take place. The same procedure was applied for $7.5 \mathrm{~g}$ of Nickel oxide and $22.5 \mathrm{~g}$ of Zinc oxide, $10 \mathrm{~g}$ of Nickel oxide and $20 \mathrm{~g}$ of Zinc oxide, $12.5 \mathrm{~g}$ of Nickel oxide and $17.5 \mathrm{~g}$ of Zinc oxide, and $15 \mathrm{~g}$ of Nickel oxide and $15 \mathrm{~g}$ of Zinc oxide.

Five different mixtures with different proportions of Zinc oxide and Nickel oxide were prepared. The summary of materials composition is shown in Table 1. The prepared composites are then ready for characterization.

\begin{tabular}{|c|c|c|c|c|c|c|}
\multicolumn{9}{c|}{ TABLE 1: COMPOSITION OF SAMPLES } \\
\cline { 2 - 7 } & \multicolumn{2}{|c|}{ NiO } & \multicolumn{2}{c|}{ ZnO } & \multicolumn{2}{c|}{ Total } \\
\cline { 2 - 7 } Sample & $(g)$ & $\%$ & $(g)$ & $\%$ & $(g)$ & $\%$ \\
\hline A & 5.0 & 16.7 & 25.0 & 83.3 & 30.0 & 100 \\
\hline B & 7.5 & 25.0 & 22.5 & 75.0 & 30.0 & 100 \\
\hline C & 10.0 & 33.3 & 20.0 & 66.7 & 30.0 & 100 \\
\hline D & 12.5 & 41.7 & 17.5 & 58.3 & 30.0 & 100 \\
\hline E & 15.0 & 50 & 15.0 & 50 & 30.0 & 100 \\
\hline
\end{tabular}

\section{CHARACTERIZATION}

Characterization of the samples were carried out using FTIR-8400S for chemical bonding and absorption pattern of the samples while SEM machine Inspect S50 microscope was used to study the surface morphology of matrix and filler.

\section{RESULTS AND DISCUSSION}

\section{A. FTIR}

Fig. 1 to 3 are the results obtained from FTIR spectroscopy for the $16.7 \%, 25.0 \%$ and $33.3 \%$ doped $\mathrm{ZnO}$ composites, respectively. They were acquired in the range of 750 to 4000 $\mathrm{cm}^{-1}$ wavenumber, with a maximum transmittance of $100 \%$.

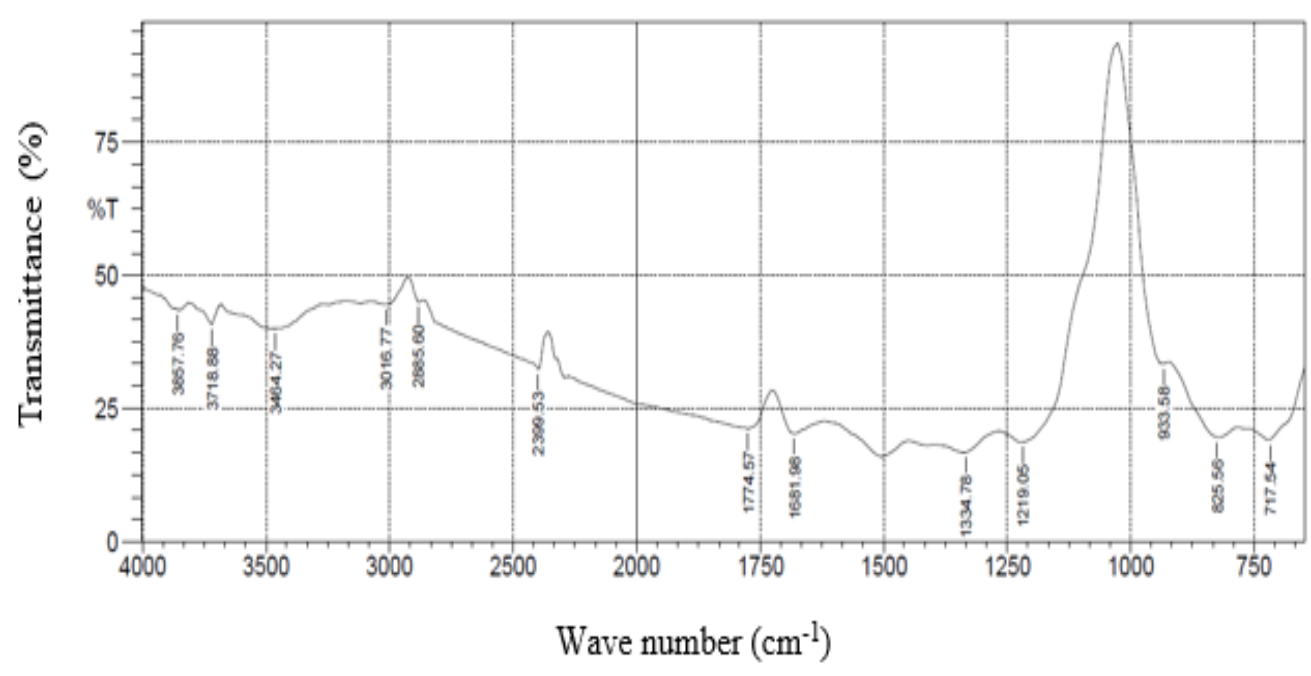

Fig. 1: FTIR Spectra for $16.7 \%$ Doped ZnO

Observation on Fig. 1, shows the absorption region of $717.54 \mathrm{~cm}^{-1}, 825.50 \mathrm{~cm}^{-1}, 1219.05 \mathrm{~cm}^{-1}, 1334.78 \mathrm{~cm}^{-1}$, $1681.98 \mathrm{~cm}^{-1}$ and $1774.57 \mathrm{~cm}^{-1}$. The highest absorbance observed is $83.3 \%$ at $1334.78 \mathrm{~cm}^{-1}$ peak corresponding to $16.7 \%$ of transmittance. The absorption band observed at $717.54 \mathrm{~cm}^{-1}$ corresponds to $\mathrm{C}-\mathrm{Cl}$ stretching vibrations and the one at $825.50 \mathrm{~cm}^{-1}$ attributes $\mathrm{C}-\mathrm{C}$ skeletal vibrations. The band at $1219.05 \mathrm{~cm}^{-1}$ corresponds to $\mathrm{C}-\mathrm{N}$ stretching vibrations. The band appearing at $1334.78 \mathrm{~cm}^{-1}$ attributed to $\mathrm{C}-\mathrm{H}$ bending vibration. The band at $1681.98 \mathrm{~cm}^{-1}$ corresponds to the symmetrical of $\mathrm{C}=\mathrm{O}$. The band at $1774.57 \mathrm{~cm}^{-1}$ attributes the $\mathrm{C}=\mathrm{O}$ stretching (Assem et al., 2013). 


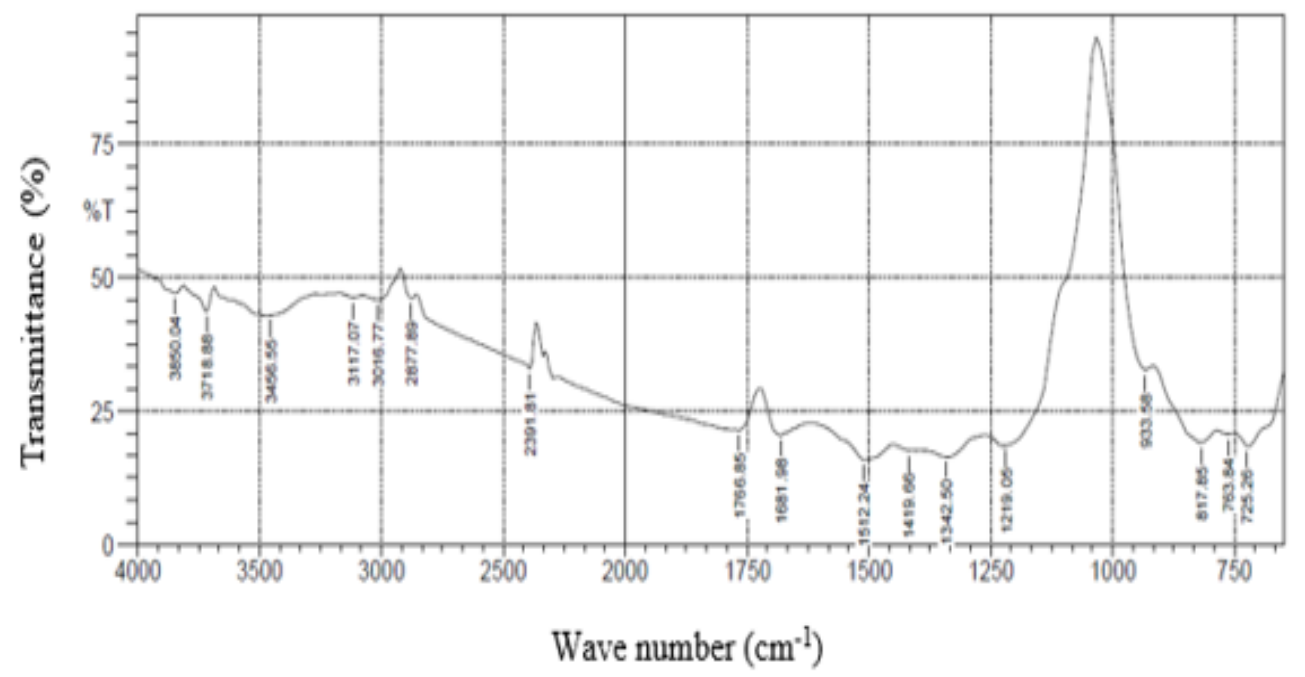

Fig. 2: FTIR spectra for $25.0 \%$ Doped ZnO

Fig. 2 shows the absorption region of $725.26 \mathrm{~cm}^{-1}, 763.84$ $\mathrm{cm}^{-1}, 817.85 \mathrm{~cm}^{-1}, 1219.05 \mathrm{~cm}^{-1}, 1342.50 \mathrm{~cm}^{-1}, 1419.00 \mathrm{~cm}^{-}$ $1,1512.24 \mathrm{~cm}^{-1}, 1681.98 \mathrm{~cm}^{-1}$ and $1766.85 \mathrm{~cm}^{-1}$. The highest absorbance recorded is around $84.1 \%$ at $1512.24 \mathrm{~cm}^{-1}$ corresponding to $15.9 \%$ of transmittance. The absorption band observed at $725.26 \mathrm{~cm}^{-1}$ and $763.84 \mathrm{~cm}^{-1}$ corresponds to strong $\mathrm{C}-\mathrm{Cl}$ stretching. The band at $817.85 \mathrm{~cm}^{-1}$ attributes C-C skeletal vibrations. The absorption at $1219.05 \mathrm{~cm}^{-1}$ corresponds to $\mathrm{C}-\mathrm{N}$ stretching vibrations. The band appearing at $1342.50 \mathrm{~cm}^{-1}$ attributed to $\mathrm{C}-\mathrm{H}$ bending vibration. The band at $1419.00 \mathrm{~cm}^{-1}$ corresponds to asymmetric $\mathrm{C}-\mathrm{H}$ bending. The absorption band at 1512.24 $\mathrm{cm}^{-1}$ attributes to $\mathrm{C}-\mathrm{H}$ skeletal vibrations. The band at $1681.98 \mathrm{~cm}^{-1}$ corresponds to the symmetrical of $\mathrm{C}=\mathrm{O}$. The band at $1766.84 \mathrm{~cm}^{-1}$ attributes the $\mathrm{C}=\mathrm{O}$ stretching (Yakubu et al., 2017).

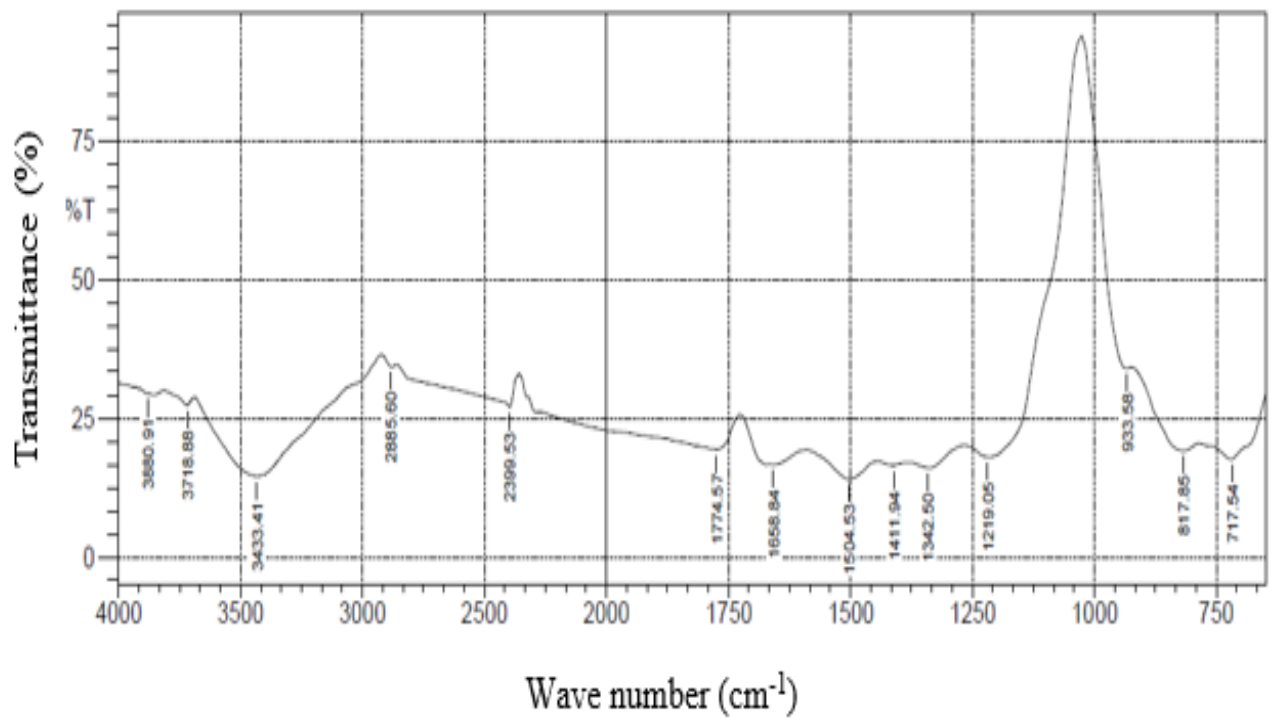

Fig. 3: FTIR Spectra for $33.3 \%$ Doped ZnO

Careful observation on Fig. 3 shows the absorption the region of $717.54 \mathrm{~cm}^{-1}, 817.85 \mathrm{~cm}^{-1}, 1219.05 \mathrm{~cm}^{-1}, 1342.50$ $\mathrm{cm}^{-1}, 1411.94 \mathrm{~cm}^{-1}, 1504.53 \mathrm{~cm}^{-1}, 1658.84 \mathrm{~cm}^{-1}, 1774.57$ $\mathrm{cm}^{-1}$ and $3433.41 \mathrm{~cm}^{-1}$. The highest absorbance observed is $86 \%$ at $1504.53 \mathrm{~cm}^{-1}$ corresponding to $14 \%$ transmittance. The absorption band observed at $717.54 \mathrm{~cm}^{-1}$ corresponds to strong $\mathrm{C}-\mathrm{Cl}$ stretching and the one at $817.85 \mathrm{~cm}^{-1}$ attributes C-C skeletal vibrations. The absorption at $1219.05 \mathrm{~cm}^{-1}$ corresponds to $\mathrm{C}-\mathrm{N}$ stretching vibrations. The band appearing at $1342.50 \mathrm{~cm}^{-1}$ attributed to $\mathrm{C}-\mathrm{H}$ bending vibration. The band at $1411.94 \mathrm{~cm}^{-1}$ corresponds to asymmetric $\mathrm{C}-\mathrm{H}$ bending. The band at $1658.84 \mathrm{~cm}^{-1}$ corresponds to the symmetrical of $\mathrm{C}=\mathrm{O}$. The band at $1774.57 \mathrm{~cm}^{-1}$ attributes the $\mathrm{C}=\mathrm{O}$ stretching and the one at $3433.41 \mathrm{~cm}^{-1}$ corresponds to strong O-H stretching (Yakubu et al., 2015a).

The $33.3 \%$ doped composites showed the highest absorption which indicates increase in absorption as doping quantity increases. Depicted in Table 2 is the summary of the quantity of absorption as evident in the FTIR analysis for all samples prepared. 
TABLE 2: SUMMARY OF ABSORPTION FOR ALL SAMPLES

\begin{tabular}{|c|c|c|}
\hline S/N & Doped ZnO (\%) & Absorption (\%) \\
\hline 1 & 16.7 & 83.3 \\
\hline 2 & 25.0 & 84.1 \\
\hline 3 & 33.3 & 86.0 \\
\hline
\end{tabular}

\section{B. SEM}

Careful observation on Fig. 6(a), shows defined coarse morphology with uniform particles that are agglomerated and forms irregular shaped particles. The darks spots indicates $\mathrm{NiO}$ with less density in distribution while the white spots indicates $\mathrm{ZnO}$ (Ahmad et al., 2015). Further observation shows a denser coarse morphology attributed to the increase in the filler content. From Fig. 6(b), the micrograph shows some whitish color image indicating the presence of zinc oxide, which are agglomerated by some doted NiO. Fig. 6(c) shows a micrographs with whitish colour image agglomerated with dark dotes of $\mathrm{NiO}$ (Karthikeyan et al., 2017). Due to the density of the sample in Fig. 6(d), more light were able to pass through it which is evident in the FTIR analysis. Observation on Fig. 6(e) shows that the zinc oxide and filler are sparsely dispersed through the matrix of the composite materials, and visible traces of white and black coloring are seen indicating the equal percentage of mixture in the sample (Yakubu et al., 2015b).

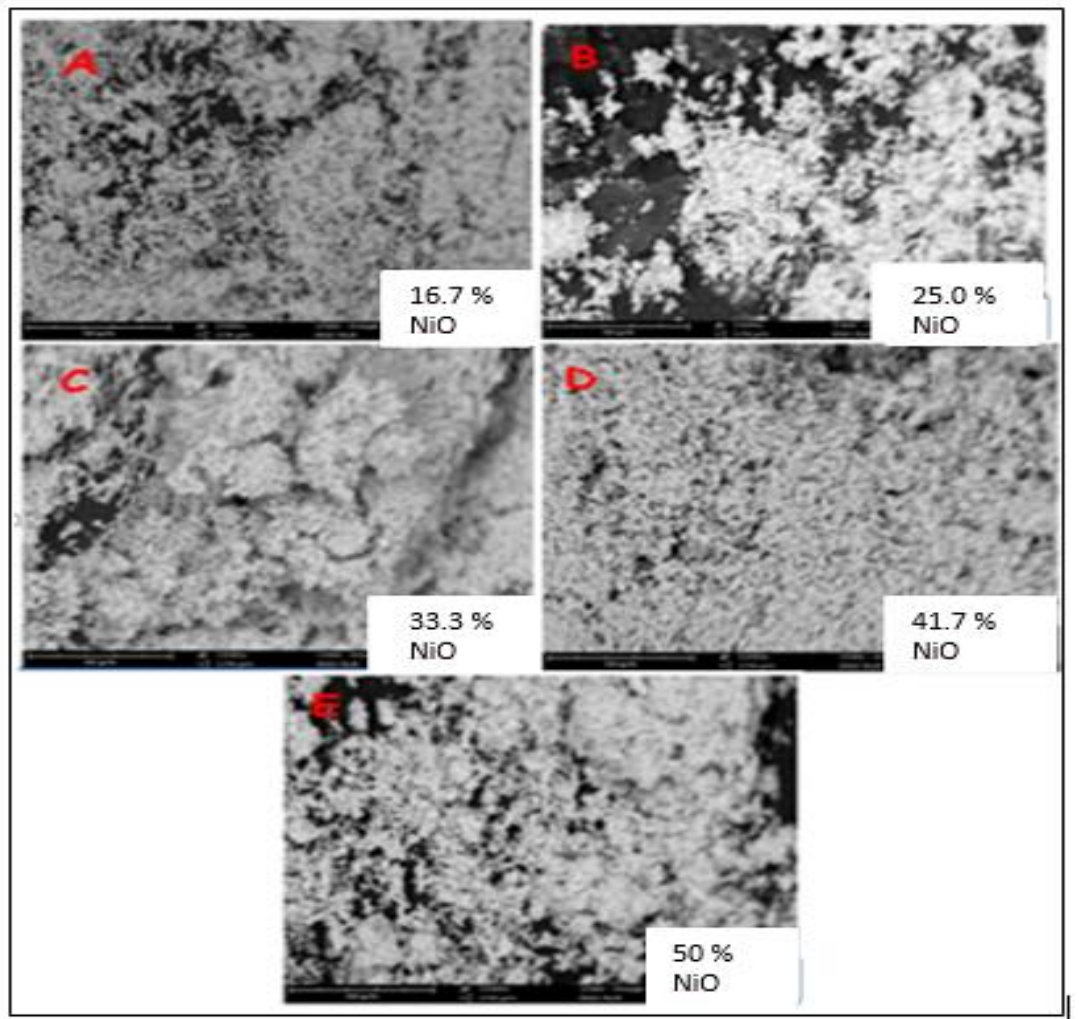

Fig. 6: SEM micrographs for doped composites

\section{CONCLUSION}

The synthesis of a doped zinc-oxide composites using simple solid stated method was successfully carried out in this research. Based on the investigations carried, result from SEM was able to distinguish between the filler and matrix for each composition. In addition the result also revealed agglomeration of particles as doping increased for all compositions. As doping increased to higher quantity, density of sample increased and this allowed for the propagation of light through the sample, which is evident in the FTIR analysis. It is then concluded that the samples prepared can be suitable for microwave absorption.

\section{REFERENCES}

[1] Abdul, J., Ghulam, Y., Waheed, Q. K., Yousaf, A. M., Rashid, M K., Muhammad, N. N., \& Ghulam, M. (2017). Electrochemical deposition of nickel grapheme composite coatings: effect of deposition temperature on its surface morphology and corrosion resistance. Royal Society of Chemistry, Vol.7, pp.311.

[2] Ahmad, F., Zulkifly, A., Mohamad, F. Z., Suzan, J., \& Yakubu, A. (2015). Dielectric characterization of oil palm fiber reinforced polycaprolactone-nickel oxide composite at microwave frequency. Procedia Environmental Sciences, 30, 273 - 278.

[3] Ajai, K. S. M., \& Sangshetty, K. (2017). Preparation, Structural and Dielectric Properties of Polyaniline-Nickel Ferrite Composites. International Journal of Materials Science, 12, 47-56.

[4] Albert, O. J., \& Abiola, M. (2017). Synthesis and structural analysis of $\mathrm{ZnO}-\mathrm{NiO}$ mixed oxide nanocomposite prepared by homogeneous precipitation. Ceramics International, 43(2017), $15424-15430$.

[5] Assem, B., Mousa, A., Mohammed, S., Abdullah, S. A., Belkheir, H., Taibi, B. H., Salim, F. H., Ahmed, B., \& Ismail, W. (2013). One Step Synthesis of NiO Nanoparticles via Solid-State Thermal Decomposition at Low-Temperature of Novel Aqua (2,9-dimethyl1,10-phenanthroline) $\mathrm{NiCl}_{2}$ Complex. Int. J. Mol. Sci., 14, 23941 23954. 
[6] AzoNano, (2013), Nickel Oxide (NiO) Nanoparticles: Properties, Applications. Retrieved from www.azonano.com/article.aspx?ArticleID $=3378$ on $7^{\text {th }}$ February, 2019.

[7] Drakakis, E., Suchea, M., Tudose, V., Kenanakis, G., Stratakis, D., Dangakis, K., Miaoudakis, A., Vernardou, D., \& Koudoumas, E. (2018). Zinc oxide-graphene based composite layers for electromagnetic interference shielding in the $\mathrm{GHz}$ frequency range. Thin Solid Films, v651, 152-157.

[8] Eman, M. F., Aboubakr, M. A., Mohammad, K. H., Adel, M. M., Chuhong, W., George, J., \& Zoheir, F. (2018). Synthesis, Characterization, and Application of Novel Ni-P-Carbon Nitride Nanocomposites. Coatings 2018, 8, 37.

[9] Jacek, k., Tadeusz, C., Stanisław, G., Kamil, S., \& Witold, L. (2018). Size Control of Cobalt-Doped ZnO Nanoparticles Obtained in Microwave Solvothermal Synthesis. Crystals, 8(179), 1-18.

[10] Karthikeyan, V., Padmanaban, A., Dhanasekaran, T., Praveen Kumar, S., \& Gnanamoorthy, G. (2017). Synthesis and Characterization of $\mathrm{ZnO} / \mathrm{NiO}$ and Its Photocatalytic Activity. Mechanics, Materials Science \& Engineering Journal, 9.

[11] Kazuaki, S., Kiyotaka, F., Nobuyuki, M., Nobuki, T., \& Satoshi, S. (2011). Microwave Absorption Properties of Polymer Modified Ni-Zn Ferrite Nanoparticles. Materials Transactions, 52(4), 740745.

[12] Mansour, A.F., Mansour, S.F. and Abdo M. A., (2015. Improvement Structural and Optical Properties of $\mathrm{ZnO} /$ PVA Nanocomposites. IOSR Journal of Applied Physics (IOSR$J A P), 7,60$.

[13] Osama, A. D., Mostafa, M. H., Khalil, K., \& Hamdy, A. K. (2015). Microstructure and Dielectric Properties of $\mathrm{ZnO}-\mathrm{SiO} 2-\mathrm{NiO}$ Composite. International Journal of Science and Research (IJSR), 316-323.

[14] Rajashekhar, B., Vishnuvardhan, T. K., Shashidhar, N., Satishkumar, K. B., Basavaraja, C., \& Chandrashekhar, M. (2015). Synthesis, Characterization and Study of Electrical Properties of
Polyaniline-NiO Nanocomposites. International Journal of Research in Engineering and Applied Sciences. 5(7), 36-46.

[15] Sani, G. D., Yakubu, A., \& Sahabi, S. (2019). Nickel Oxide (NiO) Devices and Applications: A Review. International Journal of Engineering Research \& Technology (IJERT), 8(04), 461-467.

[16] Shanavas, J., K., Asha, R., \& Beena, B., (2018). Polyaniline/Zinc Oxide Nanocomposite as a Remarkable Antimicrobial Agent in Contrast with PANI and $\mathrm{ZnO}$. Indian Journal of Advances in Chemical Science, 71.

[17] Sónia, S., Filomena, V., Marcos, A. L. R., \& Manuel F. V. (2017). Aluminum and Nickel Matrix Composites Reinforced by CNTs: Dispersion/Mixture by Ultrasonication. Metals 2017, 7, 1 .

[18] Umit, O. (2010). ZnO Devices and Applications: A Review of Current Status and Future Prospects. Proceedings of the IEEE, 98(7), 1255-1268

[19] Yakubu, A., Abbas, Z., Esa, F., \& Tohidi P., (2017). The effect of $\mathrm{ZnO}$ Nanoparticle filler on the attenuation of $\mathrm{ZnO} / \mathrm{PCL}$ Nanocomposites using microstrip line at microwave frequency. International polymer processing, Volume 30. Retrieved on $15 / 01 / 17$ from $\quad$ www.hanserelibrary.com/doi/abs/10.3139/217.015022.

[20] Yakubu, A., Zulkifly, A., Mansor, H., \& Ahmad, F. (2015a). Effect of Sintering Temperature on $\mathrm{Co}_{0.5} \mathrm{Zn}_{0.5} \mathrm{Fe}_{2} \mathrm{O}_{4}$ Nano-Particles Evolution and Particle Size Distribution. Advances in Nanoparticles, 4, 37-44.

[21] Yakubu, A., Zulkifly, A., Nor Azowa, I., \& Ahmad, F. (2015b). The Effect of $\mathrm{ZnO}$ nanoparticles Filler on Complex Permittivity of ZnO-PCL Nanocomposite at Microwave Frequency. Physical Science International Journal, 6(3), 196-202.

[22] Yuqing, Y., You, Y., Hongqing, W., Rui, X., \& Guoping, W. (2018). Morphology Control of a Nanoporous Nickel/Cobalt Double Hydroxide for Supercapacitor Electrode Materials using Halides. International Journal of Electrochemical Science, 13,466 . 